\title{
Sob o olhar da jornalista: imagem da mulher oitocentista nas páginas de um jornal
}

Gerlice Teixeira Rosa

Mestre em Linguística do Texto e do Discurso / UFMG

\begin{abstract}
RESUMO
Propomos para este artigo um recorte da dissertação de mestrado intitulada “Ethos e argumentação de Senhorinha Diniz em O Sexo Feminino" que teve como tema a análise da imagem construída pela jornalista Francisca Senhorinha da Motta Diniz em seu periódico O Sexo Feminino, veiculado em fins dos Oitocentos na cidade de Campanha, sul de Minas Gerais. Trazemos para o debate o imaginário a respeito de si que se forma através do discurso de Senhorinha Diniz. Ela cria, a partir de seu discurso, uma imagem de si mesma e configura a imagem das mulheres de sua época. Informações sobre a realidade sócio-histórica feminina são obtidas a partir dos relatos da jornalista nos editoriais analisados no corpus. A jornalista sugere a imagem de alguém capaz de gerenciar opiniões, formar conceitos e impulsionar uma modificação na maneira de pensar e agir de homens e mulheres do século 19 a partir do uso da palavra.
\end{abstract}

\section{PALAVRAS-CHAVE}

Francisca Senhorinha da Motta Diniz, imagem da mulher, jornalismo do século 19

A possibilidade de refletir sobre os feitos de mulheres de ontem e hoje, inscreve-nos na posição não só de pesquisadores, mas também de analistas e, muitas vezes, de participantes da realidade sócio-histórica recortada pela pesquisa de mestrado, a realidade feminina, da luta em prol da emancipação por meio da educação.

Trazemos para este texto o recorte da dissertação de mestrado intitulada Ethos e argumentação de Senhorinha Diniz em O Sexo Feminino, que traz à tona a imagem da mulher jornalista, escritora, uma “mulher das letras”, responsável - ou pelo menos desejosa de sê-lo - 
pelo futuro das mulheres de sua época. Trata-se da jornalista Francisca Senhorinha da Motta Diniz, redatora e editora do jornal O Sexo Feminino, veiculado em fins do século XIX na cidade de Campanha, sul de Minas Gerais.

O referido jornal foi veiculado no Brasil na segunda metade do século XIX, inicialmente, na cidade de Campanha. O lançamento do periódico data de 1873, sob a responsabilidade editorial da proprietária Francisca Senhorinha da Motta Diniz. A partir de 1875, Senhorinha se muda para o Rio de Janeiro, onde continua a produzir o jornal. Nessa cidade, veicula 22 edições até o ano de 1876. Interrompe por alguns anos as publicações e as retoma em 1889, produzindo ainda mais 10 edições.

Procuramos compreender como se dá a construção argumentativa de Senhorinha Diniz e as relações discursivas e interacionais existentes na elaboração de sua imagem e das mulheres de sua época, perpassando, assim, as representações sociais envolvidas na situação comunicativa. Percebemos que ao construir sua imagem, a jornalista constrói também o simulacro da mulher oitocentista. Esses imaginários, recuperados no discurso, revelam e ampliam nossa visão do público leitor desse jornal.

A partir das leituras do periódico é possível perceber que a proposta de $O$ Sexo Feminino esteve para além do direcionamento exclusivo para as mulheres da época. A jornalista trazia nas páginas de seu jornal uma sugestão de mudança de costumes, de pensamento e de atitudes para a sociedade do século XIX. A princípio, as ideias de Senhorinha voltavam-se apenas para a sociedade mineira de Campanha, depois para a capital do país e, com o tempo, para todo o Brasil e para outros países, como ela mesma relatou na edição de 7 de setembro de 1874. O discurso da jornalista pretende se expandir, alcançar, além do universo feminino, o campo do poder, da decisão e da mudança, por isso também é um discurso que busca ser ouvido pelos homens, os responsáveis pela tomada de decisão naquele período.

Para fundamentar nossos estudos recorremos aos postulados da Análise do Discurso (AD), no que se refere à imagem de si constituída pelo próprio sujeito do discurso. Trata-se da noção de ethos, apresentada ainda na Retórica Antiga, por Aristóteles e aprimorada na AD a partir dos anos 1980, com as pesquisas desenvolvidas por Dominique Maingueneau e Oswald Ducrot. As análises sobre o ethos discursivo ganharam força também com os trabalhos cunhados por Amossy. 
NOÇÃO DE IMAGENS DE SI

Para representar a imagem do enunciador no discurso, invoca-se uma instância subjetiva que tomará corpo à medida que o enunciador lhe der voz por meio das estratégias usadas, do seu dizer, dos índices verbais e do tom assumido no discurso. Sendo assim,

(...) a qualidade do ethos remete, com efeito, à imagem desse fiador que, por meio de sua fala, confere a si próprio uma identidade compatível com o mundo que ele deverá construir em seu enunciado. Paradoxo constitutivo: é por meio de seu próprio enunciado que o fiador deve legitimar sua maneira de dizer. ${ }^{1}$

O fiador é, portanto, esse corpo enunciante marcado historicamente que revela uma imagem discursiva e articula os elementos marcados no texto. Nos editoriais de $O$ Sexo Feminino, o corpo enunciante que surge é o de uma mulher atualizada, consciente e digna de ideais políticos direcionados para a educação feminina. Abordaremos, na sequência, a maneira como essa imagem da jornalista também contribui para a formação da ideia de emancipação da mulher e para a representação de homens e mulheres da sociedade brasileira no século XIX.

\section{A IMAGEM DE SENHORINHA DinIZ COMO SIMULACRO DA EMANCIPAÇÃO FEMININA}

Conforme afirma Maingueneau, “A eficácia do ethos se deve ao fato de que ele envolve de alguma forma a enunciação sem estar explícito no enunciado”. ${ }^{2}$ Nos editoriais, a imagem de Senhorinha aparece a partir da construção discursiva, das pistas e do ritmo conferido à enunciação, como observamos neste trecho:

O Sexo Feminino surgindo novamente na immensidade do oceano das idéas apregoadas pela liberdade, não faz mais do que concorrrer com o seo pequeno, porém franco apoio, para fazer vingar a idéa que a maioria das nações civilisadas afagam, fazendo refulgir a racional emancipação da mulher como a satisfação unica do grande principio de igualdade prégado pelo Martyr do Gólgotha. ${ }^{3}$

A jornalista assume, nos editoriais, o lugar de condutora das ações das mulheres de sua época, pois ela convida e propõe para a sociedade uma nova perspectiva para o tratamento das mulheres, como observamos no seguinte excerto:

\footnotetext{
${ }^{1}$ MAINGUENEAU. Análise de textos de comunicação, p. 99.

${ }^{2}$ MAINGUENEAU. Análise de textos de comunicação, p.98.

${ }^{3}$ DINIZ. O Sexo Feminino, 1889.
} 
Desde que subimos a tribuna universal da imprensa, redigindo este pequeno periodico, elevamos nossa voz em prol de nossos direitos, até hoje pouco prezados ou com revoltante injustiça postergados; tomamos sobre nossos fracos hombros a difficil tarefa de defendel-os em causa própria, e em que o sexo forte é juiz e parte!...

O ethos da jornalista lutadora e condutora aparece no editorial quando ela afirma: “... bradaremos, implorando ao nosso governo, aos nossos concidadãos, ás nossas amigas; assignantes desse jornal, todo o auxilio em favor da fundação de casas de educação destinadas ás meninas pobres. ${ }^{\Perp} \mathrm{O}$ fiador que transparece nessa enunciação é um indivíduo capaz de levar os leitores a assumir determinado posicionamento e o faz de maneira consciente. Tratase da imagem de alguém que tem determinação e sabe aonde quer chegar com cada atitude, com cada enunciado marcado no discurso. Assim também se caracteriza o trecho: “Avante, pois, amáveis conterrâneas! (...) Ei-nos chamando em nosso auxilio as senhoras para coadjuvarem-nos com suas luzes intelectuaes (...)”. ${ }^{6}$

Nos editoriais é construída também a imagem de uma mulher convicta de seus ideais, determinada naquilo que diz e que acredita e, acima de tudo, solidária, preocupada com a alteridade: “(...) o nosso fim, longe de ser egoístico, é mais grandioso (...)”.7 A essa figura, associa-se a mulher justa: “(...) o que queremos é justo, recto e liberal. É, pois, elemento do progressista (...).” ${ }^{8} \mathrm{O}$ fato de a jornalista afirmar que almeja a justiça, leva-nos a crer que essa característica faz parte do universo de desejos da mulher/jornalista e, portanto, esses desejos passam a fazer parte do discurso de emancipação feminina.

O ethos de mulher atualizada é recorrente no discurso da jornalista, fato que traz à tona a imagem da mulher ciente dos acontecimentos em âmbito internacional: "Como hemos dito na Alemanha, na Suissa, e até mesmo na Russia, ha hoje muitas accademias fundadas e destinadas unicamente ás mulheres”. ${ }^{9}$ Essa visão de Senhorinha a respeito do comportamento de outros países sobre a mulher tende a despertar no leitor a imagem de que a jornalista, dotada de conhecimentos e de informações atuais a respeito da temática feminina, é a pessoa legitimada a assumir o lugar de incentivadora de novos pensamentos compatíveis com a modernidade do século XIX.

\footnotetext{
${ }^{4}$ DINIZ. O Sexo Feminino, 1889.

${ }^{5}$ DINIZ. O Sexo Feminino, 1889, p. 1.

${ }^{6}$ DINIZ. O Sexo Feminino, 1889, p. 1.

${ }^{7}$ DINIZ. O Sexo Feminino, 1876, p. 1

${ }^{8}$ DINIZ, O Sexo Feminino, 1876, p. 2.

${ }^{9}$ DINIZ. O Sexo Feminino, 1876.
} 
A esperança representa no discurso elemento constituinte do ethos de Senhorinha Diniz, uma vez que ela mesma declara: “(...) o enthusiasmo que alimentam nossas esperanças." ${ }^{10}$ Verificamos também o ethos de esperança quando a jornalista afirma:

(...) esperamos ainda que alguma modificação será feita em seu orgulho. Semeêmos. Com effeito deve-se semèar para um dia poder colher-se. Com paciência e tempo a folha da amoreira se muda em setim. Esperamos que homens mais eminentes não desdenharão nossas idéas e imperfeições. ${ }^{11}$

A esperança motiva a ação da jornalista e funciona como um ponto definidor da continuidade do jornal. Senhorinha acredita e espera que aceitem suas ideias na sociedade e, consequentemente, que as mulheres invistam mais na educação e instrução para se chegar à liberdade.

O discurso da jornalista é construído de maneira a inseri-la no referencial religioso do mártir, aquele que sofre por suas crenças e opiniões. Sendo assim, todas as contrariedades e divergências enfrentadas pela jornalista são encaradas como sacrifícios de um mártir, alguém capaz de se doar inteiramente por acreditar em um ideal. Assim, Senhorinha fala da glória do jornal, apesar de seu fim: “O Sexo Feminino apparece, hade luctar, e luctar até morrer; morrerá talvez, mas sua morte será gloriosa e a posteridade julgará o perseguidor e o perseguido.”12. Em outro momento, ao relatar suas lutas, ela diz que encontrará o seu Gólgota, o calvário que é também sinal de provação e a associa diretamente à figura de Jesus Cristo.

Nos editoriais, ela apresenta-se como uma mulher religiosa, adepta a valores cristãos. Ao falar da maternidade e da importância da educação das mães na vida dos filhos, valoriza esse papel das mulheres e confere a elas um lugar quase divino. No primeiro editorial, Senhorinha finaliza sua argumentação assegurando que “(...) a sabedoria que Deus dá o diabo não a roubará”. ${ }^{13}$ Apesar de a jornalista não dizer categoricamente que crê em Deus, ela insere essa dimensão divina em seu enunciado, como forma de se posicionar também nessa oposição Deus e o Diabo.

Senhorinha mostra-se observadora, atualizada e atenta ao curso da História e aos acontecimentos que dizem respeito, especialmente, à mulher. Ela não apenas diz claramente que está noticiando os fatos, mas também revela ser atualizada a partir das datas, dos nomes citados e, até mesmo, da temática abordada: Abolição, progresso, surgimento de novos jornais

\footnotetext{
${ }^{10}$ DINIZ. O Sexo Feminino, 1876, p. 2.

${ }^{11}$ DINIZ. O Sexo Feminino, 1875, p. 1.

${ }^{12}$ DINIZ. O Sexo Feminino, 1873, p. 1.

${ }^{13}$ DINIZ. O Sexo Feminino, 1873, p. 1
} 
e citação de projetos educacionais para mulheres em outros países, como verificamos em: “Alá, o anno passado, tratava-se até de organisar um estabelecimento de ensino superior para as mulheres, o qual teria o nome de Academia das mulheres, e o mesmo da-se nos EstadosUnidos, Paris, etc., etc. (...)”. ${ }^{14}$ Senhorinha traz elementos que levam o leitor a criar a imagem da redatora do jornal como uma mulher atualizada e ligada aos fatos sobre emancipação feminina.

O discurso da jornalista promove a imagem de uma mulher humana, sensível e compassiva. A sensibilidade despertada no leitor induz o surgimento dessa mulher solidária, capaz de se compadecer de suas patrícias e apresentar para elas um novo caminho para a sua instrução, um aprimoramento da função materna. As características que compõem a identidade da jornalista e constroem sua imagem podem também ser percebidas através da citação seguinte, quando Senhorinha se dirige às mulheres incentivando-as a enfrentar as dificuldades na conquista de seus direitos: "Hemos feito vêr ás nossas conterraneas que nada no mundo é facil obter-se, sem sacrificio, e que tudo exige concurso do trabalho assiduo, para que possa ser alcançado". ${ }^{15}$ Nesse trecho a jornalista se aproxima da realidade das mulheres do século 19, mas assume uma posição de superioridade. Com o tom imperativo, Senhorinha aconselha as mulheres, alertando-as para os desafios na luta pelos direitos postergados.

\section{A IMAGEM DAS DEMAis MUlHeres DA ÉPOCA SOB O OLHAR DE SENHORINHA Diniz}

Senhorinha Diniz torna possível, em seus editoriais, a construção da imagem das mulheres do século XIX, seja de maneira clara e direta, seja de forma implícita, através de pistas discursivas. A jornalista insere-se no grupo das mulheres, apesar de, em alguns momentos, percebermos nela o ethos de superioridade, como se ela não se inserisse no universo das mulheres pouco instruídas e afetadas pela desconsideração dos homens com relação ao cumprimento dos direitos femininos. A defesa dos direitos das mulheres já prevê a imagem da mulher do século 19 como injustiçada e vítima do descaso dos homens. A situação em que viviam as mulheres no século 19 é retratada com detalhes no periódico e a partir do viés temático de uma mulher, como se segue: “A vida de humilhação que a mulher tem tido mata e matará sempre a vida de deveres santos a que Ella se consagra.”16

\footnotetext{
${ }^{14}$ DINIZ. O Sexo Feminino, 1875, p. 2.

${ }^{15}$ DINIZ. O Sexo Feminino, 1876, p. 1.

${ }^{16}$ DINIZ. O Sexo Feminino, 1889, p. 1.
} 
A jornalista apresenta aos leitores a maneira como as mulheres são vistas pelos homens, o modo como elas são tratadas por eles: “(...) a mulher não passa de um traste de casa, grosseiro e brusco gracejo.” ${ }^{~} 17$ Nos dizeres de Senhorinha Diniz, trata-se da imagem que se tem da mulher do século XIX: inferior em relação ao homem, apenas um adorno na vida do homem.

Senhorinha descreve as mulheres como submissas, que “... não conhecem seus maridos” e são vaidosas ao extremo, “(...) só cuidam no luxo e na vaidade de agradar pelos dotes exteriores, levando essa vaidade até ao ponto de venderem sua liberdade na escolha do casamento”. ${ }^{18}$ A jornalista enfatiza que elas vivem “(...) na mais rigorosa escravidão”. 19

A construção discursiva da mulher oitocentista no periódico configura a estratégia da escritora de sensibilizar seu leitor:

Sabemos tambem, nos, as mulheres, que nunca poderemos alcançar nem possuir este postulado sem lançar mãos dos meios necessarios e efficazes, e, fiquem certo, que sem obtel-o conjunctamente comnosco, as mulheres, os homens gemerão debaixo do pezo mortificador do despotismo dos outros homens. ${ }^{20}$

A mulher descrita por Senhorinha sofre uma "vida de humilhação", encontra-se em “estado desolador”, por isso justifica-se a missão da jornalista e de O Sexo Feminino de “(...) quebrar as cadêas com que por tantos séculos os homens hão arroxeando-lhe os pulsos”!.

Outra imagem de mulher retratada nos editorias retoma a mulher capaz, inteligente, a boa mãe, escolhida por Deus para assumir sua missão na terra: “Á mulher e não ao homem foi dada a missão magestatica de ser a mãi do genero humano.”21 A essa mulher Senhorinha se dirige com mais zelo, uma vez que a jornalista pretende conquistá-la, desfigurando a imagem da mulher injustiçada, pois o século das Luzes exige que surja essa senhora, independente e disposta a assumir o ideal da emancipação: “Vejamos, pois, boas mãis, o terreno é nosso, não o deixemos sem cultura, e nossa colheita será na proporção do que semeiarmos.”22 Nesse momento, o compartilhamento de Senhorinha Diniz, ao afirmar “(...) o terreno é nosso”, a

\footnotetext{
${ }^{17}$ DINIZ. O Sexo Feminino, 1873, p. 1. (grifo da autora)

${ }^{18}$ DINIZ. O Sexo Feminino, 1876, p. 1.

${ }^{19}$ DINIZ, O Sexo Feminino, 1889, p. 1. (grifo da autora)

${ }^{20}$ DINIZ. O Sexo Feminino, 1876, p. 1.

${ }^{21}$ DINIZ. O Sexo Feminino, 1889, p. 1.

${ }^{22}$ DINIZ. O Sexo Feminino, 1889, p. 2.
} 
insere no espaço de luta junto com as demais mulheres, o que promove a aproximação das imagens dessas mulheres com a mulher jornalista por se dedicarem ao mesmo ideal.

A responsabilidade pela boa educação dos filhos e pela consequente atuação de homens virtuosos na sociedade é também atribuída às mulheres, pois: “(...) formar homens bons e virtuosos, pelos meios brandos de cuja efficacia só podem dispor os affectos e amor de uma boa e verdadeira mai.” Aí se encontra o trajeto argumentativo trilhado pela jornalista: mostrar a necessidade das mulheres atuando na sociedade, evidenciar a situação em que vivem para, por fim, lançar sua proposta de emancipação racional da mulher e pedir a colaboração dos homens e mulheres das Luzes. Como relata Senhorinha em seu primeiro editorial, a sociedade oitocentista não tinha a educação da mulher como prioridade. Os ensinamentos que recebiam diziam respeito ao trato da casa, à formação de uma boa esposa e boa dona do lar. Trata-se de elementos constituintes da realidade sócio-histórica do século 19, como confirmam Araújo e Scalon:

(...) o modelo de família - homem/provedor e mulher/dona-de-casa - reflete a assimetria sexual centralizando todo o poder no homem "chefe de família/provedor”. A mulher cônjuge, dona-de-casa em tempo integral, a quem é atribuído o papel de esposa, mãe e de responsável pelo trabalho doméstico, ocupa uma posição subordinada nessa relação assimétrica. Essa posição guarda estreita relação com sua exclusão do espaço público do trabalho e com a conseqüente dependência econômica ao homem/ "chefe de família” e provedor. A mulher cônjuge ou a esposa é, por definição e por status, não provedora. Ser cônjuge ou esposa significa, portanto, não ser provedor. $^{23}$

A imagem de uma mulher dependente da figura masculina na sociedade pode ser encontrada especialmente no primeiro editorial, quando Senhorinha propõe um novo conteúdo a ser ensinado às mulheres e apresenta a dependência como um ponto negativo da realidade das mulheres: “(...) que estas meninas assim educadas não dirão quando moças estas tristes palavras: 'Si meu pai, minha mai, meu irmão, meu marido morrerem o que será de mim!!.”,24 A construção discursiva do editorial aponta para o perfil de uma mulher sem iniciativa, com pouco poder de decisão diante da própria vida. A proposta de Senhorinha, ensinar às mulheres mais do que como cuidar da casa, vai ao encontro do que afirmam os historiadores que “((...)) mesmo contra a vontade dos maridos, pais e irmãos, as mulheres opinavam”. ${ }^{25}$ Nessa afirmação, reconhece-se a dependência da mulher, mas ao mesmo tempo coloca-se em

\footnotetext{
${ }^{23}$ ARAÚJO; SCALON. Gênero, família e trabalho no Brasil, p. 126:

${ }^{24}$ DINIZ. O Sexo Feminino, Campanha, 1873, p. 1. (grifo da autora)

${ }^{25}$ CARVALHO. A imprensa na formação do mercado feminino, p. 185.
} 
evidência o desejo das mulheres de participarem do universo da opinião pública, do qual o jornalismo fazia parte.

\title{
CONSIDERAÇÕES FINAIS
}

Senhorinha Diniz apresenta-se como porta-voz das mulheres de seu tempo. A necessidade de uma mulher que assuma a fala das demais revela o reconhecimento da falta de espaço da maioria das mulheres da sociedade brasileira do século XIX, para assumir publicamente seus ideais. Surge, no discurso, o perfil da mulher oprimida e sem voz, que necessita de alguém que fale por si.

Notamos que o tom do discurso de Senhorinha e os enunciados por ela traçados nos editoriais do periódico contribuem para corroborar essa imagem da mulher oitocentista submissa, obediente ao marido, mas que, ao mesmo tempo, é potencialmente uma mulher inteligente, capaz e de destaque, cuja missão é necessária à sociedade e reconhecida por Deus, conforme afirma a jornalista, no editorial de 5 de julho de 1889: “Á mulher e não ao homem foi dada a missão magestatica de ser a mãe do genero humano.”

As descrições, dispostas nos editoriais escritos pela jornalista Francisca Senhorinha da Motta Diniz, adquirem para nós a importância de resgate histórico. Consideramos importantes os relatos e os registros históricos, nesse caso, registros também jornalísticos, que revelam o olhar do observador e do sujeito que vive e experimenta a realidade sociodiscursiva ao seu redor. A jornalista assume a função de descrever e contextualizar as vivências e as lutas femininas pela emancipação. O periódico torna-se, portanto, uma fonte histórica detalhada para a realidade e o cotidiano dos Oitocentos.

\begin{abstract}
This presents an analysis of journalist Francisca Senhorinha da Motta Diniz's journal O Sexo Feminino, published in the end of $18^{\text {th }}$ century in the city of Campanha, in the south of Minas Gerais. We bring to the debate the journalist's imaginary about herself formed through her speech. She creates, from her speech, an image of herself and thus establishes an image of the women of her time. Information about the social-historical reality of women is known from the reports of the journalist in the editorials in the corpus examined. The journalist suggests the image of someone who is able to
\end{abstract}


construct opinions, to form concepts and to encourage a change in the way

of thinking and of acting in the $19^{\text {th }}$ century.

\section{KEYWORDS}

Francisca Senhorinha da Motta Diniz, image of the woman, nineteenth century journalism

\section{REFERÊNCIAS}

ARAÚJO, C.; SCALON, C. Gênero, família e trabalho no Brasil. In: OLIVEIRA, Z. L. C. A provisão da família: redefinição ou manutenção dos papéis? Rio de Janeiro: Editora FGV, 2005. p. 123-148.

CARVALHO, M. J. M. A imprensa na formação do mercado feminino. In: NEVES, L. M. B.; MOREL, M.; FERREIRA, T. M. B. História e imprensa: representações culturais e práticas de poder. Rio de Janeiro: DP\&A, 2006.

DINIZ, F. S. M. O Sexo Feminino. Campanha: Typ. Do Monarchista, 1873.

DINIZ, F. S. M. O Sexo Feminino. Campanha: Typ. Do Monarchista. 1875.

DINIZ, F. S. M. O Sexo Feminino. Rio de Janeiro: Lombaertes \& Filho, 1876.

DINIZ, F. S. M. O Sexo Feminino. Rio de Janeiro: Lombaertes \& Filho, 1889.

MAINGUENEAU, D. Análise de textos de comunicação. 3 ed. Trad. C. P. S. Silva. São Paulo: Cortez, 2004. 